\title{
FISCAL POLICY REACTION FUNCTION AND THE SUSTAINABILITY OF FISCAL POLICY IN UKRAINE
}

\author{
Artem Vdovychenko \\ National Bank of Ukraine \\ Email: artem.vdovychenko@bank.gov.ua
}

\section{ABSTRACT}

This study analyzes the fiscal policy reaction function with switching regimes. We use Logistic Smooth Transition Regressions (LSTR) to show that fiscal policy in Ukraine during the study period remained largely in passive mode, switching to active mode during periods of a high output gap and elevated debt-to-GDP ratio. An important finding is that the fiscal policy reaction function is nonlinear. Specifically, the response of fiscal policy to the output gap is asymmetric: fiscal policy is pro-cyclical during periods of economic growth but neutral in recession.

\section{JEL Codes: E62, H62, H63}

\section{Keywords: fiscal policy, fiscal sustainability, active/passive fiscal policy, regime switching}

\section{INTRODUCTION}

The response by fiscal policy to changes in the macroeconomic environment or the statistical evaluation of fiscal rules is a theme that is discussed intensively in academic circles. A promising topic for discussion is the nonlinearity of the fiscal policy reaction function (FPRF) and switching of fiscal policy regimes. However, economists have mainly focused on fiscal policy in advanced economies or small open economies with developed democracies. Emerging markets have some inherent features like high pro-cyclicality and low sustainable debt limits, per the findings of Mendoza and Ostry (2007), but they remain largely unexamined. Ukraine is a small open economy that has experienced exponential debt growth over the last ten years and therefore represents an interesting case for testing the fiscal policy reaction function.

From a policy perspective, this study aims to identify the causes of the exponential growth in public debt in Ukraine based on the evolution of fiscal policy approaches. We estimate the FPRF for Ukraine from quarterly data, like Burger and Marinkov (2012), and analyze fiscal policy regimes using regressions with breaks in time series and splines for the level of public debt and the phase of the business cycle. We then use an approach similar to Legrenzi and Milas (2013) to estimate LSTR models with output gaps and debt ratios in the role of transition variables to better understand the causes of switching between fiscal policy regimes.

The paper is structured as follows: the second section reviews the literature on the relationship between the concept of fiscal sustainability and the fit of the FPRF and provides an overview of fiscal policy regimes in emerging markets; the third section describes the methods we prefer for estimating the FPRF given Ukraine's switching regimes; in the fourth section we describe the dataset; in the fifth section, we present the results of the estimates; the last section outlines a summary of the findings and implications for fiscal policy.

\section{LITERATURE REVIEW}

Fiscal policy targets have long been the topic of discussion. Based on existing theory and standard assumptions, researchers argue that the objective of fiscal policy is to regulate the cyclical fluctuations of an economy or to maintain fiscal sustainability. The FPRFs are designed to determine the achievement of fiscal policy goals in different countries or in different time periods. The fit of the FPRF itself can be quite different, but it must include an indicator of public debt and the position of the economic cycle (output gap). The coefficient of the public debt variable is a primary interest because, along with the co-integration of fiscal variables, a statistically significant positive reaction of the primary deficit on changes in the level of debt is a sign of sustainable fiscal policy (Bohn, 1998). A positive debt level coefficient in the FPRF means a government reduces the budget deficit in response to debt growth and increases the deficit when debt decreases. By reviewing the empirical literature that analyzes the FPRFs, we see there are conventional modifications used by researchers to better describe the behavior of fiscal indicators. De Mello (2005) represents the general equation of the FPRF as follows: 


$$
b_{i, t}=a_{0}+a_{1} b_{i, t-1}+a_{2} d_{i, t-1}+a_{3} C_{i, t}+u_{i t}
$$

where $b_{i, t}$ is the ratio of the primary budget balance to nominal GDP; $b_{i, t}$ is the ratio of public debt to nominal GDP; and $C_{i, t}$ is a set of control variables for the different levels of budgets $i$ in time period $t$. To determine the control variables, de Mello (2005) used the following intertemporal budget constraint:

$$
b_{t}+\left(r_{t}-g_{t}\right) d_{t-1}=\Delta d_{t}+\Delta m_{t}+\left(\pi_{t}+g_{t}\right) m_{t-1}
$$

where $\pi_{t}$ represents inflation; $m_{t}$ is the ratio of the monetary base to GDP; and $g_{t}$ is the real GDP growth rate. Using this relationship, the author shows that cyclical output and inflation should be included as control variables in equation (2) to account for revenues from seigniorage.

In some studies, the authors try to account for the nature of small open economies by including specific variables in the FPRF. Penalver and Thwaites (2006) assumed that public debt consists of foreign and domestic debt and, consequently, the debt cost and the dynamics of these components will be influenced by variables like the real exchange rate and foreign and domestic interest rates. The authors concluded that the uncertainty of macroeconomic forecasts and the response of variables like the public debt-to-GDP ratio and interest rates significantly strengthen the reaction of fiscal policy to changes in public debt.

Another common practice is the inclusion of dummies to extract fiscal policy features that were a characteristic for a given political regime in the FPRF (Burger and Marinkov, 2012). In some studies, economists analyze fiscal policy reactions not in the form of the response of the total primary deficit, but as the response of specific components of income and expenditure (Claeys, 2008). These studies allow conclusions to be made concerning the exact budget components that adjust the overall budget balance in response to fluctuations in the level of debt and macroeconomic indicators.

Changes or switches to the fiscal policy approach complicates FPRF estimates because the simple linear model reflects the averaged coefficients of the different approaches. In the literature, the solution to this problem was found in the use of models with switching regimes. Fiscal policy regimes can be introduced into the models exogenously or endogenously. The introduction of exogenous regimes occurs when a researcher has an a priori notion of the period in which the properties of fiscal policy could change. Technically, this is done by evaluating the FPRF for different time periods (Gali and Perotti, 2003) or by introducing dummy variables to, for example, exclude specific political events (Burger and Marinkov, 2012). Another approach is to identify regime-switching based on endogenous information when under the influence of a transition variable, the FPRF coefficients change, and these changes are estimated based on the information contained in the data itself. Legrenzi and Milas (2013) used a Smooth Transition Regression (STR) to estimate the simple FPRF, which assumed a switch between the coefficients of the business cycle and the short-run relationship between the primary budget deficit and public debt. In this study, transition variables include the level of public debt in the previous year, the business cycle stage in the previous year, and the difference between the level of public debt and the state-varying threshold, based on an index of financial pressure. The results show that the countries studied (Greece, Ireland, Portugal, and Spain) have had sustainable fiscal policies from the 1960 s to the present. At the same time, during periods of increasing financial pressure, these countries reduced marginal debt levels and thereafter corrected debt levels to re-establish fiscal sustainability. Along with other approaches, Burger et al. (2011) use a Threshold Autoregressive model (TAR), where the output gap serves as a transition variable and the threshold is set at zero. Thus, fiscal policy becomes counter-cyclical during periods of recession. Favero and Monacelli (2005), Claeys (2008), Burger and Marinkov (2012) use regressions with Markov switching regimes where the regimes are determined endogenously. Burger and Marinkov (2012) use this approach to reflect the shift of fiscal policy from passive to active and vice versa in South Africa. Claeys (2008) used this approach to analyze the characteristics of fiscal policy in different regimes. The author also investigated the reaction of different budget expenditure and income components. Favero and Monacelli (2005), in addition to the identification of fiscal policy regimes in the US, also studied their synchronization with monetary policy regimes, in doing so enriching the analysis of macroeconomic conditions of government and central bank actions.

The FPRF is also useful in characterizing fiscal policy as active or passive. This classification is slightly different than the counter-/pro-cyclical or sustainable/unsustainable fiscal policy characterization as both coefficients (debt and output gap) must be switched in the FPRF. Under this classification, active fiscal policy comprises fiscal actions not related to changes in public debt, i.e. through fiscal instruments used by the government to influence other macroeconomic parameters like level of output, employment, etc. (Leeper, 1991). Passive policy includes actions that are limited by public debt levels and intertemporal budget considerations. In this type of regime, the main objective of fiscal policy is to maintain or achieve a sustainable level of public debt. In the empirical context, this means that in the case of passive fiscal policy, the coefficient of public debt is positive and statistically significant. Alternately, a statistically significant coefficient on other control variables, especially the output gap, is a sign of an active fiscal policy.

There are numerous published works on the sustainability of fiscal policy for different categories of countries. In general, the conclusion is that on average, fiscal policy in emerging market countries responds to the parameters of sustainability. Abiad and Ostry (2005) emphasized that along with the general sustainability of fiscal policy, exceeding the threshold levels for debt diminishes the responsiveness to debt for emerging market countries. This speaks to the nonlinearity of the reaction of 
fiscal policy depending on the economic conditions. The authors argue that there are two types of fiscal policy in developing countries. They state that the ability of policymakers to maintain fiscal solvency through higher primary balances appears to decrease in countries with mean and median debt ratios above $50-60 \%$.

Mendoza and Ostry (2008) studied fiscal solvency in industrialized countries, emerging markets, and countries with high and low debt levels. They concluded the fiscal sustainability criteria are satisfied in general by all groups of countries, however, a government's ability to meet the criteria of fiscal sustainability greatly reduces as debt levels rise. In contrast to existing literature, they did not find that the responsiveness to debt increases when debt exceeds threshold levels in panel regressions for advanced countries, but it does diminish for emerging market countries.

Ghosh et al. (2013) examined the phenomenon of "fiscal fatigue", referring to the switching of fiscal policy in an unsustainable regime in response to a high debt ratio. In the sample of developed countries, the authors empirically proved the existence of "fiscal fatigue" by constructing a cubic FRFP. This is a specific modification of the model with three fiscal policy regimes. The authors show that at low debt levels, the relationship between budget deficits and debt levels is not significant or even negative. As debt increases, the responsiveness of fiscal policy also increases. However, at high debt levels, that reaction begins to weaken and then decreases at extremely high debt levels. Estimates suggest the responsiveness of fiscal policy to debt levels starts to decrease at $90-100 \%$ of GDP and becomes negative when debt levels approach $150 \%$ of GDP. This conclusion contradicts Bohn's findings (1998) for the US, that the fiscal reaction increases as debt increases. The authors explain the phenomenon of "fiscal fatigue" by the government's inability to increase primary balances at the same pace as the pace of debt growth.

Another facet of fiscal policy is its reaction to fluctuations in GDP. The response of fiscal policy to a business cycle is a wellresearched topic. In general, the work has found that in emerging markets, fiscal policy is pro-cyclical or neutral. An important issue in the context of fiscal sustainability is the symmetry of the fiscal policy response to different phases of the economic cycle. In April 2015, the IMF reported that symmetry in the fiscal response in good and bad times is important for three main reasons: to rebuild buffers ahead of the next cyclical downturn, to reduce the risk of overheating, and to avoid growth in public debt in successive cycles. According to the report, emerging markets are asymmetrical in their fiscal policy response to economic cycles. In periods of recession, fiscal policy tends to be counter-cyclical, while during periods of economic growth, policy is pro-cyclical. The IMF showed that a systematic asymmetric response is associated with a non-negligible increase in the debt-to-GDP ratio. Under benign macroeconomic assumptions, asymmetric stabilization could, after 20 years, result in a debt-to-GDP ratio much higher than with symmetric stabilization.

In terms of switching between passive and active fiscal policy approaches, the asymmetry of the fiscal response to business cycle phases could carry a hidden threat to debt levels. If the government pursues a passive fiscal policy (pro-cyclical and sustainable) during periods of a positive output gap, this will result in an increased budget deficit and a decreased debt ratio. This approach will contribute to an overheating of the economy and create the conditions for an increase in debt and a narrowing of fiscal space in subsequent periods. This type of policy approach cannot be considered prudent. Those conditions are better suited to an active fiscal policy, which can cool down an economy during a growth phase and contribute to an increase of fiscal resources for counter-cyclical action in future economic downturns. In this study, we show that passive fiscal policy during economic booms in Ukraine has led to the uncontrolled growth of public debt.

\section{THE METHOD}

To estimate the FPRF for Ukraine, we start with the standard formula:

$$
\operatorname{prsurpl}_{t}=a_{0}+a_{1} \operatorname{prsurpl}_{t-4}+a_{2} \mathrm{debt}_{t-4}+a_{3} \text { gap }_{t-4}+a_{4} \text { pol }_{t}+\sum_{\mathrm{j}=1}^{\mathrm{n}} b_{j} D_{j}+u_{t^{\prime}}
$$

where prsurpl is the ratio of the primary budget deficit to GDP; debt is the ratio of total government and guaranteed debt to GDP; gap is the cyclical deviation of nominal GDP from potential GDP; pol is a political dummy, representing the two quarters prior to presidential or parliamentary elections; and $D$ is a dummy to control for data outliers. To estimate the function, we use quarterly data, which forces us to enter a four-quarter lag for the explanatory variables to the formula. It is more natural to study the reaction of fiscal policy using annual data, since the budget is adopted annually and the government often reacts to economic changes in the subsequent year. However, using annual data would reduce the number of observations for Ukraine, since the calculations cover the years 1998-2015. Moreover, quarterly data are more appropriate for identifying specific fiscal policy regimes. Using the practice of Burger and Marinkov (2012), we use quarterly data with a fourth lag as a substitute for annual data with one lag. In studies with fiscal rules estimates, quarterly data are often used when explaining the variables included in the model without lags. That leads mainly to an estimate of the automatic reaction of fiscal parameters to economic conditions. At the same time, the discretionary reaction is largely ignored because the time required to implement fiscal decisions will not allow them to be executed within one quarter. We therefore note that our use of variables with a four-quarter lag highlights the discretionary government response. The model (3) is estimated using Ordinary Least Squares (OLS), Generalized Method of Moments (GMM), and Limited Information Maximum Likelihood (LIML). The use of lags in the explanatory variables reduces endogeneity risk, but the model also includes a lag for the dependent variable, which retains 
the probability of endogeneity and bias of all coefficients. We treated prsurpl, debt, and gap as endogenous variables and used variables that reflect external economic conditions as instruments. In particular, we used variables that reflect the state of the global economy (the average growth rate for OECD countries), the state of global commodity markets that influence the Ukrainian economy (agricultural raw materials index, metals price index, non-fuel price index, sunflower oil price, wheat price index, fertilizers price index), and the real effective exchange rate as an indicator of relative prices between Ukraine and its major trading partners. Those variables are used because Ukraine's economy is small and open, meaning Ukraine is a pricetaker on international commodity markets. Therefore, international economic trends are weakly dependent on the events and political decisions in Ukraine (exogeneity), but they strongly influence the economic situation in Ukraine itself (thus they should be strong instruments).

Given the growing literature on political business cycles, we also include in the FPRF a political variable. On the belief that fiscal manipulations by incumbent politicians during pre-election periods help explain changes in budget parameters, their inclusion in the model should improve the efficiency of estimates.

Since we assume the FRFP is nonlinear, we test the presence of structural breaks in the model's (3) coefficients. Significant changes in the business cycle and debt coefficients would signal changes to fiscal policy in Ukraine.

To determine fiscal regimes depending on the phase of the economic cycle and debt levels, we run a set of models with splines, which distinguish the coefficients of the FPFF depending on the data being above or below the spline. For the splines, we used the zero level of the business cycle (when the GDP gap is equal to zero), a sample mean of the debt ratio, and positive/ negative changes in public debt.

Determining the splines exogenously is subjective, which can result in an incomplete understanding of the process of fiscal policy regime-switching. To identify switching thresholds based on the statistical results, we applied a Logistic Smooth Transition Regression (LSTR) in the following form:

$$
\operatorname{prsurpl}_{t}=\phi^{\prime} \mathbf{x}_{t}+\theta^{\prime} \mathbf{x}_{t} G\left(\gamma, c, s_{t-n}\right)+u_{t^{\prime}} \quad t=1, \ldots, T,
$$

where $\mathbf{x}_{t}$ is the vector of the exogenous explanatory variables; $\phi=\left(\phi_{0}, \phi_{1}, \ldots, \phi_{m}\right)^{\prime}$ and $\theta=\left(\theta_{0}, \theta_{1}, \ldots, \theta_{m}\right)^{\prime}$ are parameter vectors of size $((m+1) \times 1), u_{t} \sim$ i.i.d. $\left(0, \sigma^{2}\right)$. For that type of model, we assumed the following transition function:

$$
G\left(\gamma, c, s_{t-n}\right)=\left(1+\exp \left\{-\gamma \prod_{k=1}^{K}\left(s_{t-n}-c_{k}\right)\right\}\right)_{-1}, \gamma>0,
$$

where $S_{t-n}$ is a transition variable, which in our study is used with a lag $\mathrm{n} ; c_{k}$ is a location parameter from vector $\mathrm{c}=\left(\mathrm{c}_{1}, \ldots, C_{K}\right){ }^{\prime}$ with restrictions $\mathrm{c}_{1} \leq \ldots \leq c_{K}$; and $\gamma$ is the slope. In our approach:

- The same variables as in the model (3) were used as exogenous variables;

-We assumed the coefficients of the public debt ratio and the output gap will switch between fiscal policy regimes;

- Fiscal policy switches regimes depending on the magnitude of the transition variable $\left(s_{t-n}\right)$ relative to the variable $s_{\mathrm{k}^{\prime}}$ which is the switching threshold;

- A regime is weighted using the $\theta_{m}$ coefficient, and $\gamma>0$ defines the smoothness of the transition between regimes.

This type of model and the construction of it are described in Teräsvirta (2004), while Legrenzi and Milas (2013) established the notion of this type of FPRF specification. In this study, unlike in previous works, we test the LSTR model for the size of vector $c=\left(c_{1}, \ldots, c_{K}\right)^{\prime}$. The most common cases are regressions with $K=1$ and $K=2$. In the case of $K=1$, the model parameters vary monotonically based on the functional relation with $s_{t-n}$ until policy switches to another regime. These models describe the asymmetric behavior of variables at high and low values of the transition variable. The transition between regimes can be smooth. The LSTR model with $K=2$ (LSTR2) assumes that the coefficients vary symmetrically around the point $\left(c_{1}+c_{2}\right) / 2$, which is within the range of the transition variable. These models are used when the variables behave in the same manner at high and low magnitudes of $s_{t-n}$, but switch to another regime while $s_{t-n}$ is intermediate.

The LSTR2 regression is a three-regime model, two of which are symmetrical. The work of Ghosh et al. (2013) serves as evidence for the possibility of the existence of this type of nonlinearity in fiscal policy. The authors, while using a cubic regression empirically, show that fiscal policy becomes less responsive to debt at extremely low and high debt levels, but reacts to increasing debt at moderate debt levels.

Before building a model, researchers should run a series of tests for nonlinearity in relationships caused by the transition variables. As transition variables, we test the ratio of total public debt to GDP and the output gap. Variables with lags ranging from $t-4$ to $t-8$ were tested. These potential transition variables were chosen based on the assumption that a change of fiscal policy to another regime is caused by the phase of the economic cycle and the overall level of public debt. 
The lags for the transition variables are chosen based on the assumption that the government determines the parameters of the following year's budget based on the previous year's information on public debt and the stability of the financial system.

As an alternate variable to test the robustness of our results, we use the ratio of the cyclically adjusted primary deficit to potential GDP $(c a b)$, instead of the ratio of the primary deficit to GDP. The $c a b$ is an indicator that better identifies discretionary fiscal policy, thus allowing us to be confident the results are not biased by an automatic reaction.

\section{DATA}

We use quarterly data for 1998-2015, the maximum available period. Data on public debt is sourced from the Ministry of Finance's web-based database, budget data is taken from the website of the State Treasury of Ukraine, and macroeconomic data is sourced from the database of the National Bank of Ukraine (NBU). The prsurpl variable was seasonally adjusted to control for its high seasonality. Debt was estimated as the logarithmic of the ratio of total government and guaranteed debt to seasonally adjusted GDP1. Before estimating the output gap (gap) using the Hodrick-Prescott filter, nominal GDP was transformed into logarithms and seasonally adjusted. As a proxy for the cab, we used residuals from a regression of the form:

$$
P R_{D E F t}=c_{0}+c_{1} G D P_{\text {cyclet }}+e_{t},
$$

where $P R_{D E F t}$ is the seasonally adjusted primary deficit; $G D P_{\text {cycle }}$ is the seasonally adjusted GDP gap in absolute terms; and $e_{t}$ represents the residuals that do not include the automatic response of fiscal policy on cyclical fluctuations of GDP. Therefore, we assume that the automatic response of fiscal parameters presents itself during a quarter, while the government's discretionary actions have a lag of at least one quarter.

The time series we include in our model is stationary, which is important for the consistent estimation of parameters of the FPRF. The output gap is stationary by definition, but the unit root tests of public debt and primary deficit to GDP ratios typically produce mixed results. This is especially true for Ukraine, where public debt levels were distorted by a powerful structural shock in 2008, invalidating standard tests. However, Bohn (1998) and Bohn (2007) noted that these time series have considerable inertia, so determining their stationarity is challenging. Accordingly, stationarity should be based not on the statistical tests that lose their power in a relatively small sample and with the presence of structural breaks, but on economic logic. As shown in Table 1, ADF, KPSS, and Elliot-Rothenberg-Stock (ERS) Point optimal tests were conducted for the formal conclusions on the stationarity of time series. The order of lags in ADF was selected based on the AIC information criterion, all tests were conducted based on the assumption that intercept is stationary.

\section{Table 1. Results of stationarity testing for FPRF variables}

\begin{tabular}{|c|c|c|c|}
\hline \multirow{2}{*}{ Variable (period) } & $A D F(H 0: \rho=1)$ & KPSS (HO: $\rho \neq 1)$ & $\operatorname{ERS}(H 0: \rho=1)$ \\
\hline & t-statistics & LM-statistics & t-statistics \\
\hline prsurpl (1998q1-2015q4) & $-5.3(p<0.01)$ & $0.3(p=0.10)$ & $2.2(p<0.05)$ \\
\hline$c a b(1998 q 1-2015 q 4)$ & $-4.7(p<0.01)$ & $0.7(p<0.05)$ & $1.6(p<0.01)$ \\
\hline gap (1998q1-2015q4) & $-3.5(p<0.01)$ & $0.1(p>0.10)$ & $1.1(p<0.01)$ \\
\hline debt (1998q1-2015q4) & $-0.5(p>0.10)$ & $0.2(p>0.10)$ & $12.2(p>0.10)$ \\
\hline d_debt (1998q2-2015q4) & $-7.6(p<0.01)$ & $0.2(p>0.10)$ & $0.7(p<0.01)$ \\
\hline
\end{tabular}

The stationarity tests show that the cycles of GDP and the primary surplus, with very high probability, are stationary processes. At the same time, according to the ADF test, the cyclically adjusted budget balance and the first differences of the debt ratio are stationary, but confirm their stationary according to the KPSS test only at the level of approximately 5\%. For the final conclusions, the ERS test was conducted because of the disadvantages of the ADF and KPSS tests, namely that they are severely distorted by size and have difficulty in distinguishing highly persistent stationary processes from nonstationary processes.

\footnotetext{
${ }^{1}$ The level of public debt is the stock variable and quarterly GDP is the flow variable. As a result, on graphs and in tables, debt, which equals log (total government and guaranteed debt / seasonally adjusted GDP), yields high values. Taking the exponent and dividing this figure by 4 yields an approximation of the average yearly ratio of debt-to-GDP.
} 


\section{ESTIMATION RESULTS}

According to the proposed approach, we estimated the model of type (3) for the prsurpl and cab variables using OLS, GMM, and LIML. The results are presented in Table 2. A dummy variable (d_2010q03) represents the third quarter of 2010 when the government of Ukraine issued and sold approximately UAH 16.5 billion in VAT bonds, artificially increasing VAT revenues and distorting budgetary statistics. Along with the coefficients, the table contains statistics to judge the accuracy of standard errors estimation and bias. Note that when identifying problems with autocorrelation or the heteroskedasticity of errors, we applied the HAC variance-covariance matrix to mitigate the problems with standard errors. For the models with the instruments, we provide the statistics, characterizing the degree of the instruments' exogeneity and their explanatory power. The test results indicate that the selected instruments are exogenous, but may be weak. The underidentification test does not indicate a problem, but the $\mathrm{F}$ statistics in the Weak identification test indicates that the maximal IV bias relative to OLS could reach $20 \%$. For this reason, along with the GMM, we used LIML, which is less sensitive to the problems of weak instruments.

Table 2. The results of linear FPRF estimations for Ukraine, 1998-2015

\begin{tabular}{|c|c|c|c|c|c|c|}
\hline & \multicolumn{2}{|c|}{ OLS } & \multicolumn{2}{|c|}{ GMM } & \multicolumn{2}{|c|}{ LIML } \\
\hline & prsurpl & $c a b$ & prsurpl & $c a b$ & prsurpl & $c a b$ \\
\hline Constant & 0.01 & $0.01 * *$ & 0.01 & 0.01 & 0.01 & 0.01 \\
\hline d_2010q03 & $-0.08 * * *$ & $-0.08 * * *$ & $-0.06^{*}$ & $-0.08^{*}$ & $-0.06^{*}$ & $-0.09 * *$ \\
\hline $\operatorname{prsurpl}_{t-4^{\prime}} c a b_{t-4}$ & $0.24 *$ & $0.38 * * *$ & $0.68 * *$ & $0.69 * * *$ & $0.74 * *$ & $0.88 * * *$ \\
\hline$g a p_{t-4}$ & -0.09 & -0.07 & $-0.19 * *$ & $-0.13^{*}$ & $-0.21 * * *$ & 0.01 \\
\hline$d \_d e b t_{t-4}$ & $0.04 * *$ & $0.04 *$ & 0.00 & 0.00 & 0.01 & 0.09 \\
\hline $\operatorname{pol}_{t}$ & $-0.01 * * *$ & $-0.01^{* *}$ & $-0.02 * *$ & $-0.02 *$ & $-0.02 * *$ & $-0.02 *$ \\
\hline Obs. & 67 & 67 & 61 & 61 & 61 & 61 \\
\hline Adj. R-squared & 0.27 & 0.29 & & & & \\
\hline Autocorrelation in residuals test & $p=0.03$ & $p=0.42$ & $p=0.19$ & $p=0.13$ & $p=0.17$ & $p=0.17$ \\
\hline Heteroscedasticity test & $p=0.42$ & $p=0.34$ & $p=0.26$ & $p=0.31$ & $p=0.35$ & $p=0.25$ \\
\hline Sargan statistics & & & $p=0.46$ & $p=0.61$ & $p=0.51$ & $p=0.34$ \\
\hline Endogeneity test & & & $p=0.00$ & $p=0.00$ & $p=0.00$ & $p=0.00$ \\
\hline Underidentification test & & & $p=0.01$ & $p=0.00$ & $p=0.01$ & $p=0.03$ \\
\hline Weak identification test & & & 5.86 & 6.76 & 5.86 & 3.74 \\
\hline
\end{tabular}

Note: $* * *$, and $* * *$ denote statistical significance at $10 \%, 5 \%$, and $1 \%$, respectively. Autocorrelation in the residuals test - Breusch-Godfrey Serial Correlation LM Test (4 lags) for OLS estimates and Cumby-Huizinga test for GMM and LIML. Heteroscedasticity test - Breusch-Pagan-Godfrey test for OLS estimates and Pagan-Hall general test for GMM and LIML. The Cragg-Donald Wald F and Kleibergen-Paap rk Wald F statistics (in case of heteroscedasticity or serial correlation) are used to test weak identification issue.

The results in Table 2 show that Ukraine's fiscal policy was in a passive state during the reported period. The OLS models indicate a positive and statistically significant response of the primary deficit and the cyclically adjusted primary deficit to public debt. Meanwhile, the output gap coefficients show the pro-cyclical nature of fiscal policy, although this lacks statistical significance. Judging by the signs of the coefficients, OLS and the methods of instrumental variables indicate identical characteristics for Ukraine's fiscal policy. The decrease of the statistical significance of the coefficients in the models estimated by GMM and LIML can be explained by the loss of efficiency inherent to those methods of estimation.

The linear FPRF in model (3) contains coefficients that are not stable. To show this, we conducted a series of tests for changes in regression coefficients that are caused by structural breaks in the data. The tests for the unknown dates of the structural breaks included coefficients of the variables in which we are most interested (Table 3). 


\section{Table 3. The results of the Wald test for structural breaks}

\begin{tabular}{|c|c|c|}
\hline Coefficients included in the test & Break date & Prob. $>$ chi $^{2}$ \\
\hline \multicolumn{3}{|c|}{ Dependent variable: $\operatorname{prsurp}_{t}$} \\
\hline$g a p_{t-4}, d_{-} d e b t_{t-4}$ & $2006 q 3$ & $p=0.03$ \\
\hline$g a p_{t-4^{\prime}}$ & $2006 q^{3}$ & $p=0.02$ \\
\hline$d_{-} d e b t_{t-4}$ & $2011 q 1$ & $p=0.08$ \\
\hline \multicolumn{3}{|c|}{ Dependent variable: $\mathrm{cab}_{t}$} \\
\hline$g a p_{t-4}, d_{-} d e b t_{t-4}$ & $2006 q^{3}$ & $p=0.56$ \\
\hline$g a p_{t-4^{\prime}}$ & $2006 q 3$ & $p=0.26$ \\
\hline$d_{-} d e b t_{t-4}$ & $2008 q 1$ & $p=0.47$ \\
\hline
\end{tabular}

The results in Table 3 allow us to make several conclusions. First, the structural breaks in the data, which lead to an instability of the coefficients, are better identified in a model of the primary surplus. Second, both the debt ratio and the output gap show changes in the coefficients, what enables us to identify 3Q 2006 as the common structural break date for these variables. Based on that date, we ran regressions of fit (3) using Least Squares with Breaks. When the model showed serial correlation and heteroskedasticity errors, we used the HAC matrix to estimate the standard errors. We also estimated the FPRF with a structural break in $4 Q 2008$, the start of the powerful downturn of the Ukrainian economy and of the financial sector. This crisis was notable for the rapid depreciation of the hryvnia, falling stock valuations, the explosion of CDS spreads on Ukrainian bonds, and the adoption of special fiscal programs in response to the debt crisis and the recession. Based on these events, the crisis in 4Q 2008 may mark a change in the direction of fiscal policy. ${ }^{2}$ Table 4 outlines the estimation results.

\section{Table 4. Least Squares with Breaks estimation of the FPRF}

\begin{tabular}{|c|c|c|c|c|}
\hline \multirow[t]{2}{*}{ Variables } & prsurpl & $c a b$ & prsurpl & $c a b$ \\
\hline & \multicolumn{2}{|c|}{$1999 q 2-2006 q 3$} & \multicolumn{2}{|c|}{$1999 q 2-2008 q 4$} \\
\hline$g a p_{t-4}$ & $0.15^{* *}$ & 0.12 & 0.54 & 0.01 \\
\hline \multirow[t]{2}{*}{$d_{-} d e b t_{t-4}$} & $0.03 * *$ & 0.02 & 0.01 & 0.01 \\
\hline & \multicolumn{2}{|c|}{$2006 q 4-2015 q 4$} & \multicolumn{2}{|c|}{$2009 q 1-2015 q 4$} \\
\hline $\operatorname{gap}_{t-4}$ & $-0.22 * *$ & $-0.10 * * *$ & $-0.20 * * *$ & $-0.10 * *$ \\
\hline \multirow[t]{2}{*}{$d \_d e b t_{t-4}$} & $0.03 * * *$ & $0.04 * * *$ & $0.04 * * *$ & $0.05^{* * *}$ \\
\hline & \multicolumn{4}{|c|}{ Non-Breaking Variables } \\
\hline Constant & $0.01 * *$ & $0.01 * *$ & 0.01 & $0.01 *$ \\
\hline d_2010q03 & $-0.09 * * *$ & $-0.09 * * *$ & $-0.09 * * *$ & $-0.09 * * *$ \\
\hline $\operatorname{prsurpl}_{t-4}, c a b_{t-4}$ & $0.25^{* *}$ & $0.39 * * *$ & $0.26^{* *}$ & $0.41 * *$ \\
\hline $\operatorname{pol}_{t}$ & $-0.02 * * *$ & $-0.01 * *$ & $-0.01 * * *$ & $-0.01 * *$ \\
\hline Obs. & 67 & 67 & 67 & 67 \\
\hline Adj. R-squared & 0.33 & 0.28 & 0.26 & 0.23 \\
\hline $\begin{array}{l}\text { Breusch-Godfrey Serial Correlation } \\
\text { LM Test (lag4) }\end{array}$ & $p=0.91$ & $p=0.74$ & $p=0.49$ & $p=0.53$ \\
\hline Breusch-Pagan-Godfrey test & $p=0.08$ & $p=0.06$ & $p=0.01$ & $p=0.05$ \\
\hline
\end{tabular}

According to the results, prior to the breaking points, Ukraine's fiscal policy was close to an active-sustainable or a neutral state. After the identified points, fiscal policy turned passive relative to economic trends. The 302006 is notable as it was the 
starting point of the strongest cyclical economic growth in Ukraine's history (Figure 1). This period of strong economic growth in Ukraine was driven by the robust growth of the global economy and, consequently, the sharp rise in global commodity prices. The growth was fastest in the commodity markets that make up Ukraine's major exports .

Figure 1. The debt ratio and the output gap in Ukraine

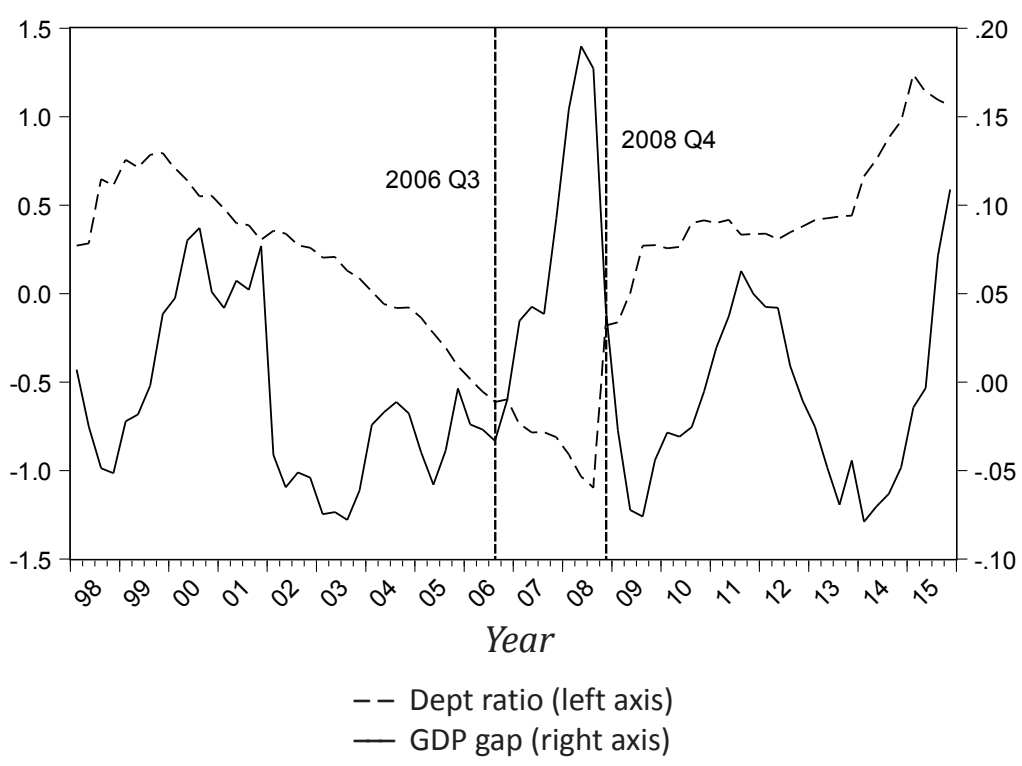

This period of cyclical economic growth was marked by the overheating of the global economy and finished with the global financial crisis and the material decline in global output. The boom period for Ukraine's economy at the end of 2006 resulted in fiscal policy switching into passive mode and remaining in that mode until 4Q 2015. From 3Q 2006 to 4Q 2008, under conditions of economic growth and decreasing debt, this meant increasing the budget deficit. However, the collapse of the global economy and international capital markets and the resulting lack of external financing for Ukraine led to the uncontrolled growth of public debt, which led the passive fiscal policy regime to remain for some time. Two major endogenous factors prompted the exponential growth of Ukraine's public debt. Ukraine's passive fiscal policy approach in 2006-2008 made it impossible to form reserves for future economic downturns (a narrower fiscal space) and contributed to the accumulation of debt. Meanwhile, inexpensive financial resources on the overheated international capital markets encouraged the government to increase Ukraine's external debt, which was negatively affected after the devaluation of the hryvnia in 2008-2009.

Thus, the switching of fiscal policy, whereby the budget deficit is tied to the level of debt and cannot be used to finance counter-cyclical actions, took place not during the crisis that began in late 2008, but during the period of economic growth. The switch was caused by a non-prudential government policy that was dependent on steady economic growth and a fixed exchange rate.

The Least Squares with Breaks approach enables us to match the prevailing trends with breaks in time, but that approach does not allow an analysis of the economic factors that caused the policy change. To analyze changes to fiscal policy regimes depending on debt dynamics and the phase of the business cycle, we have run regressions with splines. For the output gap, the spline was set at zero to observe the behavior of the FPRF coefficients during periods of economic overheating and recessions. Similarly, we established a spline for debt growth. For the level of public debt, the spline was set at the mean value for the 1998-2015 period. The results of the estimates (Table 5) indicate that relative to the business cycle phase, fiscal policy switched to passive mode during periods of a positive output gap. During economic recession, fiscal policy is neutral - there is no counter-cyclical reaction and no definitive correction of the budget deficit in-line with changes to the level of debt. This explains why in previous models with structural breaks, Ukraine's fiscal policy was shown to be in a neutral mode from 1998 to Q3 2006 - for most of this period, Ukraine had a negative output gap. Regressions with the splines on the debt measures indicate that the fiscal policy is generally sustainable and increases its responsiveness to debt changes with the growth in the debt burden. At the same time, conditional on the level of debt, there is no statistically significant relationship between the budget deficit and the business cycle. Regardless of the level of debt, fiscal policy is pro-cyclical, although this result is not statistically significant. 


\section{Table 5. The fiscal policy reaction function with splines}

\begin{tabular}{|c|c|c|c|c|c|c|}
\hline \multirow{2}{*}{$\begin{array}{l}\text { Spline } \\
\text { Dependent variable }\end{array}$} & \multicolumn{2}{|c|}{$\begin{array}{l}\text { Negative output gap (-) } \\
\text { Positive output gap (+) }\end{array}$} & \multicolumn{2}{|c|}{$\begin{array}{l}\text { Debt decrease (-) } \\
\text { Debt increase (+) }\end{array}$} & \multicolumn{2}{|c|}{$\begin{array}{l}\text { Below average debt level } \\
(-) \\
\text { Above average debt level } \\
(+)\end{array}$} \\
\hline & prsurpl & $c a b$ & prsurpl & $c a b$ & prsurpl & $c a b$ \\
\hline Constant & $0.01 * * *$ & $0.02 * *$ & 0.01 & $0.01 *$ & 0.01 & $0.01 * *$ \\
\hline d_2010q03 & $-0.07 * * *$ & $-0.07 * * *$ & $-0.08 * * *$ & $-0.08 * * *$ & $-0.09 * * *$ & $-0.09 * * *$ \\
\hline $\operatorname{prsurpl}_{t-4} / \mathrm{cab}_{t-4}$ & $0.20 *$ & $0.30 * * *$ & 0.20 & $0.30 * * *$ & $0.22 *$ & $0.37 * * *$ \\
\hline$p_{\text {t }}$ & $-0.01 * * *$ & $-0.01 * * *$ & $-0.02 * * *$ & $-0.01 * *$ & $-0.01 * * *$ & $-0.01 * *$ \\
\hline $\operatorname{gap}_{t-4}(-)$ & 0.19 & 0.16 & -0.11 & -0.1 & -0.12 & -0.10 \\
\hline $\operatorname{gap}_{t-4}(+)$ & $-0.25 * * *$ & $-0.19 * * *$ & -0.02 & 0.01 & -0.01 & -0.01 \\
\hline$d \_d e b t_{t-4}(-)$ & 0.05 & 0.03 & 0.04 & 0.04 & $0.03 * *$ & 0.04 \\
\hline$d_{-} d e b t_{t-4}(+)$ & $0.03 * * *$ & $0.04 *$ & $0.03 * * *$ & $0.04 * * *$ & 0.07 & 0.06 \\
\hline Obs. & 68 & 68 & 68 & 68 & 67 & 67 \\
\hline Adj. R-squared & 0.31 & 0.3 & 0.27 & 0.28 & 0.28 & 0.29 \\
\hline Autocorrelation in residuals test & 0.11 & 0.37 & 0.01 & 0.17 & 0.08 & 0.50 \\
\hline Heteroscedasticity test & 0.26 & 0.24 & 0.38 & 0.25 & 0.31 & 0.33 \\
\hline
\end{tabular}

The models with splines indicate that the switching of fiscal policy takes place under the influence of the business cycle phase (from neutral to passive), while debt growth only increases the sustainability of fiscal policy. As mentioned in the discussion of the existing literature, the asymmetry of fiscal policy regimes relative to the output gap holds risks for fiscal sustainability. A pro-cyclical fiscal policy during periods of economic growth and the lack of pro-cyclicality during downturns leads to a narrowing of the government's fiscal space and creates the conditions for an accumulation of debt in the future, which is not always accompanied by positive economic trends. The sustainability of fiscal policy during periods of a positive output gap (debt reduction and increased budget deficit) cannot always compensate for the negative impact of the asymmetry. The asymmetry in response to budget deficits is not complete. During periods of a negative output gap, fiscal policy is neutral. On the one hand, this can help reduce debt, because during economic downturns the government does not increase the budget deficit. On the other hand, the lack of counter-cyclical policy prolongs the economy's time in depression, which affects public finances and can increase the level of debt.

While running the regressions with splines we first define the thresholds for regime switching at our own discretion and we believe the FPRF coefficients are homogeneous in the sub-samples of the data we have chosen. However, this approach is subjective and it makes sense to allow the data to identify the conditions of regime switching. For this, we apply the LSTR model (4), which allows us to test several potential transition variables for the presence of nonlinearities between the FPRF variables. Parameter $\gamma$ controls the slope of the transition function according to Teräsvirta (2004), when $\gamma \rightarrow \infty$ the LSTR1 model approaches the Markov switching regression model with two regimes that have equal variances. The LSTR2 model, in this case, converges to switching the regression model with three regimes such that the outer regimes are identical and the middle regime is different from the other two. Thus, in constructing the LSTR model we can identify the variables that induce regimeswitching and assume a slower transition between the regimes than in the Markov switching models.

As noted in the description of the methodology, as candidates for the transition variables we tested the ratio of public debt to GDP (debt) and the output gap (gap). The testing methods are described in Teräsvirta (1994, 1998). ${ }^{3}$ In our results, we present estimations based on those transition variables, which made it possible to identify the nonlinear relationships between the variables in the FPRF. 
Table 6. LSTR1 models of FPRF

\begin{tabular}{|l|}
\hline Dependent variable \\
\hline Transition variable \\
\hline Constant \\
\hline$d_{-} 2010 q 03$ \\
\hline pol ${ }_{t}$ \\
\hline prsurpl \\
\hline$d$ debt $_{t-4} / \mathrm{cab}_{t-4}$ \\
\hline gap \\
\hline$\gamma$ \\
\hline $\mathrm{C} 1$ \\
\hline
\end{tabular}

Obs.

Adj. $R^{2}$

Test of No Error

Autocorrelation (p-value)

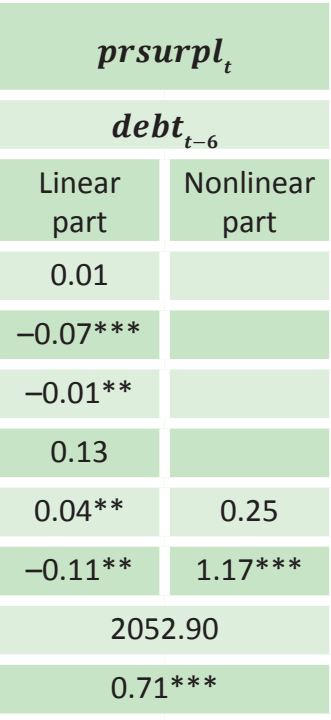

65

0.53

\begin{tabular}{|c|c|}
\hline $\operatorname{lag} 1=$ & $\operatorname{lag} 2=$ \\
\hline 0.94 & 0.98 \\
\hline $\operatorname{lag} 3=$ & $\operatorname{lag} 4=$ \\
\hline 0.99 & 0.98 \\
\hline
\end{tabular}

\begin{tabular}{|c|c|}
\hline \multicolumn{2}{|c|}{$\boldsymbol{p r s u r p l}_{\boldsymbol{t}}$} \\
\hline \multicolumn{2}{|c|}{$\boldsymbol{g a p}_{\boldsymbol{t - 8}}$} \\
\hline $\begin{array}{c}\text { Linear } \\
\text { part }\end{array}$ & $\begin{array}{c}\text { Nonlinear } \\
\text { part }\end{array}$ \\
\hline $0.01^{* * *}$ & -0.01 \\
\hline-0.01 & \\
\hline$-0.01 * * *$ & \\
\hline 0.20 & \\
\hline $0.11^{*}$ & -0.10 \\
\hline-0.10 & $0.70^{* *}$ \\
\hline \multicolumn{2}{|c|}{7.40} \\
\hline \multicolumn{2}{|c|}{$0.07^{* * *}$} \\
\hline
\end{tabular}

63

0.43

\begin{tabular}{|c|c|}
\hline $\operatorname{lag} 1=$ & $\operatorname{lag} 2=$ \\
0.1 & 0.14 \\
\hline $\operatorname{lag} 3=$ & $\operatorname{lag} 4=$ \\
0.3 & 0.41
\end{tabular}

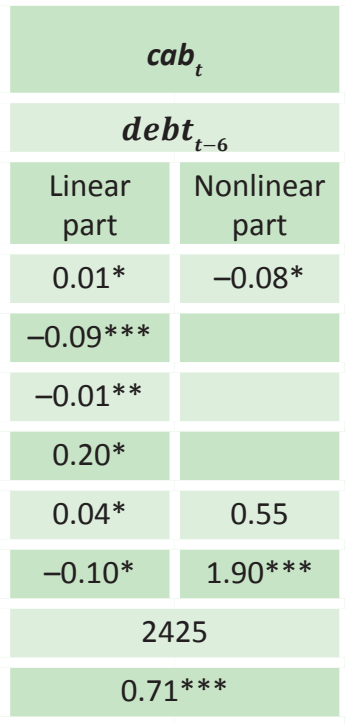

65

\subsection{5}

\begin{tabular}{|c|c|}
\hline $\operatorname{lag} 1=$ & $\operatorname{lag} 2=$ \\
0.29 & 0.44 \\
\hline $\operatorname{lag} 3=$ & $\operatorname{lag} 4=$ \\
0.59 & 0.75
\end{tabular}

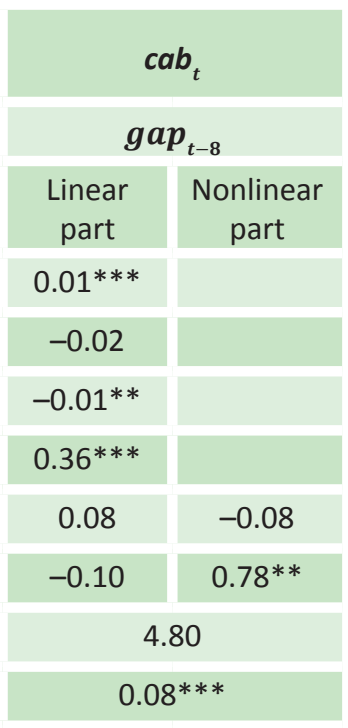

63

0.38

\begin{tabular}{|c|c|}
\hline \multicolumn{2}{|c}{0.38} \\
\hline $\operatorname{lag} 1=$ & $\operatorname{lag} 2=$ \\
0.41 & 0.58 \\
\hline $\operatorname{lag} 3=$ & $\operatorname{lag} 4=$ \\
0.63 & 0.84
\end{tabular}

Table 6 outlines the results of modeling the FPRF using the LSTR approach. The tests for nonlinearity with the use of transition variables described above constantly preferred the LSTR1 models. This means fiscal policy has two regimes, one of which is formed after a transition variable (nonlinear part) reaches a certain value. A set of tests for nonlinearities allowed us to identify two types of transition variables: the public debt to GDP ratio with a six-quarter lag and GDP with an eightquarter lag. The models for the primary (prsurpl) and cyclically adjusted budget deficit (cab) yielded approximately the same results - after crossing the transition variables with high thresholds $(C(1)$ for gap $=0.08, \max =0.18 ; C(1)$ for debt ratio $=0.71$, $\max =1.23$ ), fiscal policy switches over to an active regime. The gamma coefficients show rapid change between regimes when the transition variable is $d e p t_{t-6^{\prime}}$, while gap $p_{t-8}$ causes a relatively slow change. The statistical insignificance of $\gamma$ is justified by the fact that for large values of gamma and a small data sample, it is difficult to determine the curvature of the transition function because it requires a large number of observations near the $\mathrm{C} 1$ point. This increases the standard errors of $\gamma$. Another point is that the standard t-statistic cannot be interpreted correctly since it is designed to test the hypothesis $\gamma=0$, while in LSTR $\gamma$ is restricted: $\gamma^{s}>0$ (Teräsvirta 2004).

The thresholds for fiscal policy regime-switching and the transition functions of LSTR1 regressions are presented in Appendix 1 . These charts reflect the probability of the FPRF to be in the nonlinear part of the model, or in other words, they allow the identification of periods of FPRF switching during an active fiscal policy regime. Since the thresholds for the transition variables are relatively high, switches to fiscal policy in an active state are rare and short-lived.

The debt level threshold for fiscal policy changes in an active state (counter-cyclical and unsustainable) coincides with the results in Abiad and Ostry (2005), where they demonstrated that in emerging markets, fiscal policy becomes unsustainable after the debt-to-GDP ratio exceeds 50-60\%. The threshold estimated by the LSTR1 model for Ukraine is: $e^{0.71} / 4=0.5$.

It is important to note that the logic of fiscal policy regime-switching in Ukraine assumes the feasibility of the LSTR2 model for its description. According to our results, regime-switching takes place during the peak business cycle and debt levels. If there is a constant negative correlation between the business cycle and debt, the periods of high debt must be accompanied by low output gaps, and vice versa. This would mean that fiscal policy switches over to an active regime in two cases: when the debt ratio is high ${ }^{4}$ (low output gap) and when the debt ratio is low (high output gap). The attempt to describe Ukraine's FPRF using a three-regime model (LSTR2) was not successful owing to a low statistical significance of the coefficients. We attribute this to the lack of a negative significant correlation between the debt level and the business cycle for the significant part of our sample.

${ }^{4}$ Under high and low, we mean above or below a certain threshold level that is statistically significant. 
We also tested for the presence of nonlinear relationships in Ukraine's FPRF provided only one variable switches $\left(d \_d e b t t-4\right.$, or gapt-4). Based on the results, we ran several LSTR1 regressions that are not reported in this article. Those models suggest the coefficients of the business cycle are more likely to switch, while the debt ratio coefficients are generally monotonous. This finding confirms the results of the spline regressions (Table 5), which pointed to the radical switch of the output GDP gap coefficients during different economic phases. However, the LSTR1 models also point to the fact that Ukraine's fiscal policy was not in a passive state for the full range of positive values of the business cycle. At extremely high values of the GDP gap, policy shifted to an active regime.

The shift of fiscal policy from passive to active mode at a high GDP gap in our view is explained by the fact that the budget deficit cannot be expanded for long under conditions of economic growth. Eventually, the fiscal balance must be corrected, which would have features of counter-cyclicality. In addition, if the economic growth is accompanied by a decrease in debt levels, the debt becomes problematic for a government that pays little attention to it. Switching over fiscal policy in an active regime with a high debt ratio corresponds to the "fiscal fatigue" phenomenon described in Ghosh et al. (2013). It can be explained by the fact that after a certain threshold, the government is no longer able to reduce the budget deficit and no longer responds to high debt levels.

\section{CONCLUSIONS AND POLICY IMPLICATIONS}

This study explores the fiscal policy reaction function with switching regimes in Ukraine.

The application of alternate approaches to testing breaks in the data allows us to identify that the policy switched over to passive mode in 3Q 2006. We found that Ukraine's fiscal policy remained largely passive over 2006-2015, but it occasionally switched over to active mode during periods of a high output gap and debt-to-GDP ratio.

In addition, we document an incomplete asymmetry in the response of the budget balance to the phase of the business cycle: fiscal policy is pro-cyclical during periods of economic growth, but neutral in recession. Therefore, our findings explain the exponential growth in debt over the last decade and confirm that the pro-cyclicality prevented the creation of sufficient fiscal space to maintain an active fiscal policy during a recession.

All the findings are robust with respect to the choice of estimation techniques and measures of the budget deficit and are in-line with previous empirical works. Like Mendoza and Ostry (2007), we found that Ukraine's fiscal policy switches over to an active regime after the debt-GDP ratio crosses the $50 \%$ threshold and this switch occurs with a high output gap. Unlike Abiad and Ostry (2005), but in-line with Bohn (2005), our findings suggest fiscal policy strengthens in response to debt. The identified nonlinear effects are consistent with the so-called "fiscal fatigue" described by Ghosh et al. (2013). This implies that fiscal policy switches to an unsustainable regime at low and high levels of public debt, when the government becomes incapable of reducing the budget deficit and does not respond to growing debt after a certain threshold.

From a practical point of view, the identification of the incomplete asymmetry in the response of fiscal policy during different phases of the economic cycle (pro-cyclical fiscal policy in an upturn and neutral in a downturn) resulted in an additional increase in debt in a downturn and a missed opportunity to create fiscal space during an upturn. As a result, because debt levels were high, the government was not able to use fiscal stimulus during the recession in 2014-2016.

A resolution to this situation is to (1) in the medium-run consolidate the budget to reduce and stabilize the level of debt; and (2) develop fiscal rules that restrict pro-cyclical fiscal policy during future economic boom periods. 


\section{APPENDIX 1.}

The probability of FPRF switching to a nonlinear regime (active fiscal policy) and the dynamics of transition variables compared with the estimated thresholds

Transition function. Depended variable - prsurpl. Transition variable $-\operatorname{debt}(t-6)=0.71$

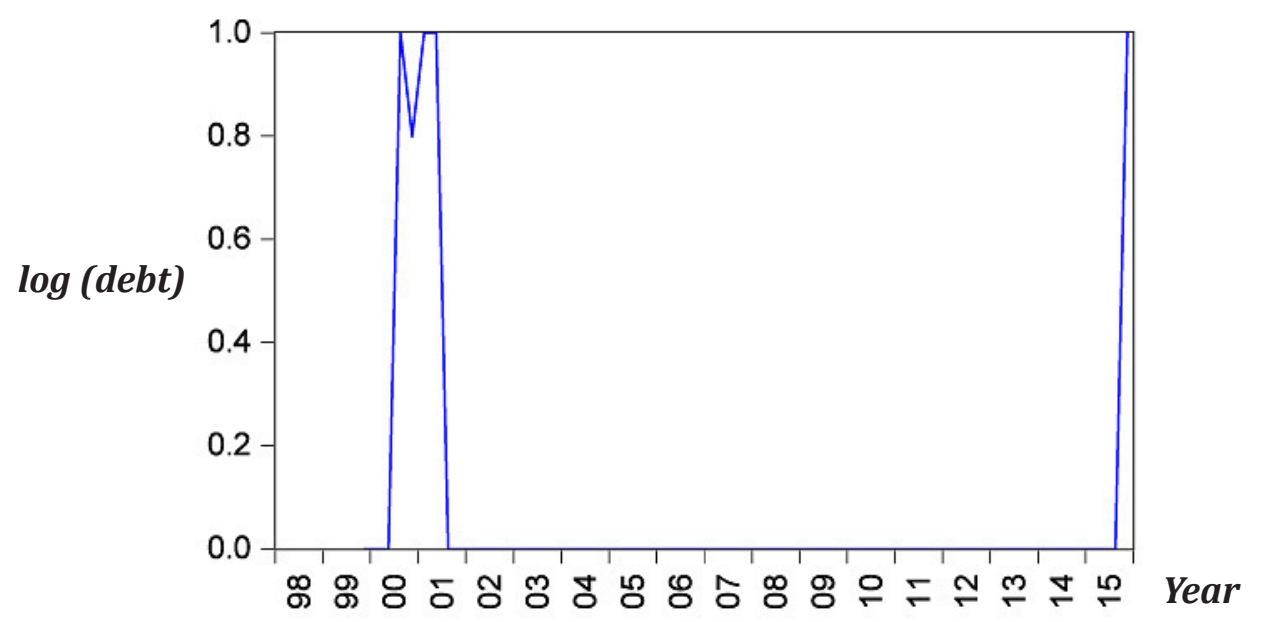

Transition function. Depended variable $-\boldsymbol{c a b}$. Transition variable $-\operatorname{debt}(\boldsymbol{t}-6)=0.71$

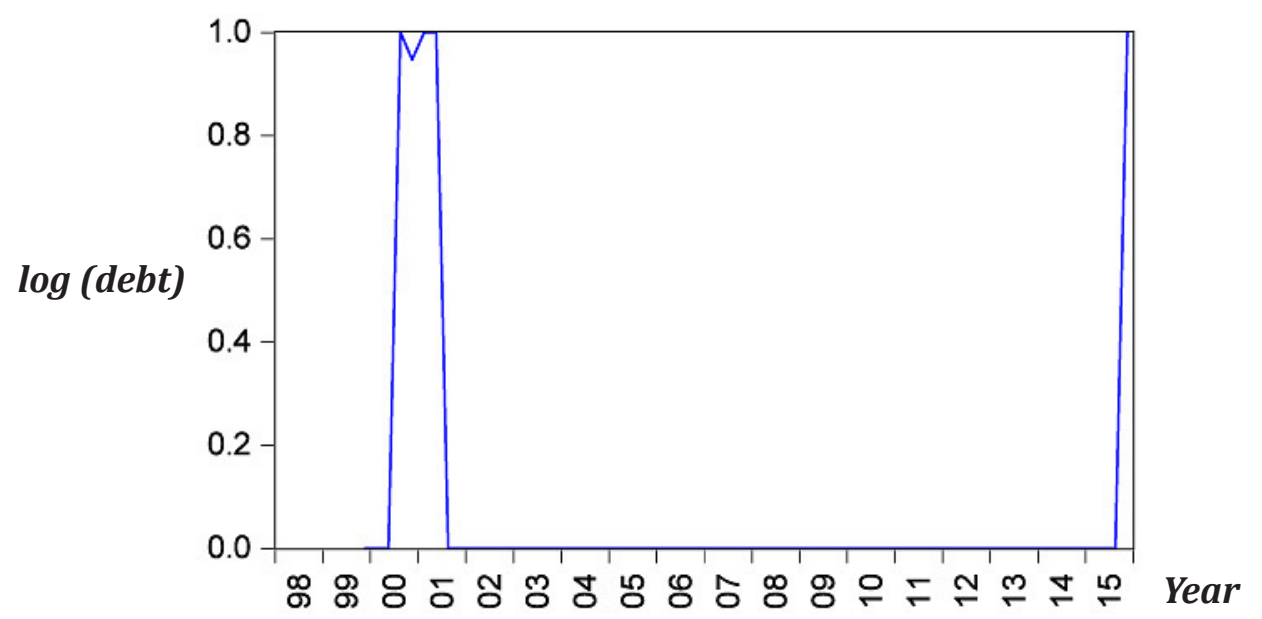

debt

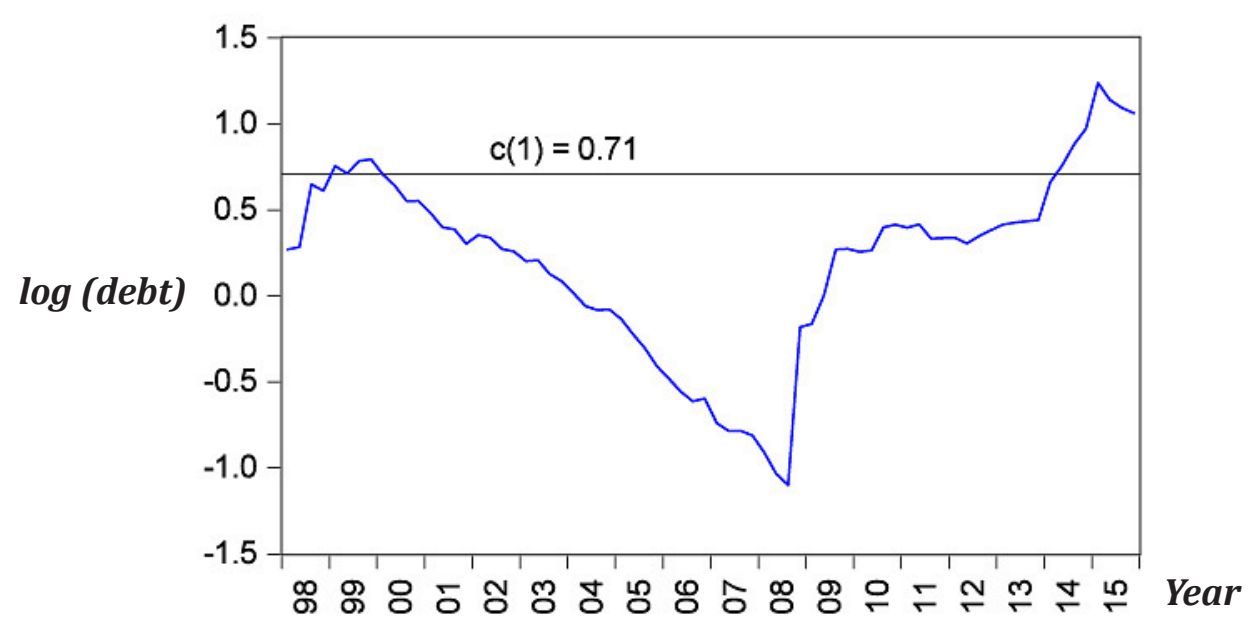


The probability of FPRF switching to a nonlinear regime (active fiscal policy) and the dynamics of transition variables compared with the estimated threshold

Transition function. Depended variable - prsurpl. Transition variable $-g a p(t-8)=0.08$

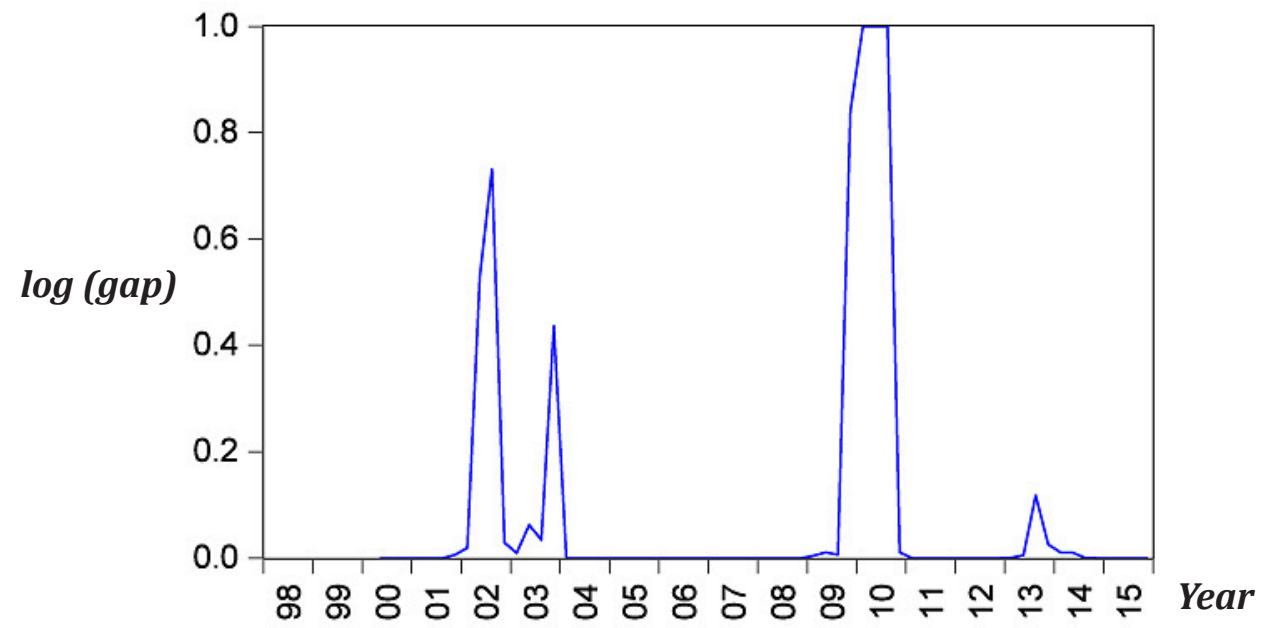

Transition function. Depended variable $-c a b$. Transition variable $-g a p(t-8)=0.08$

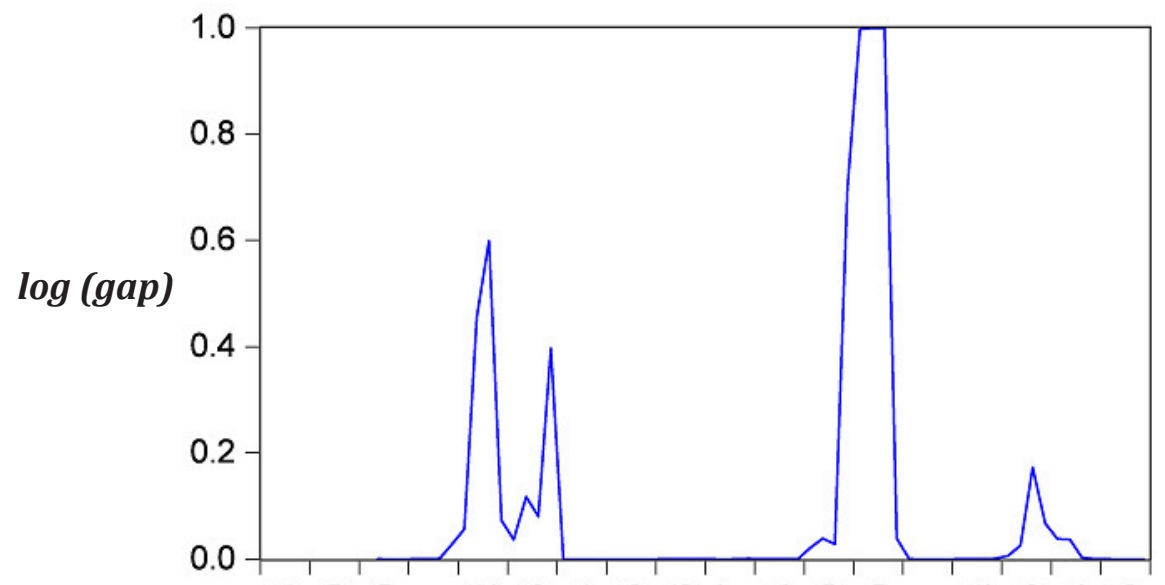

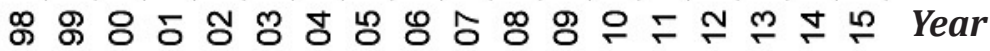
GPD cycle

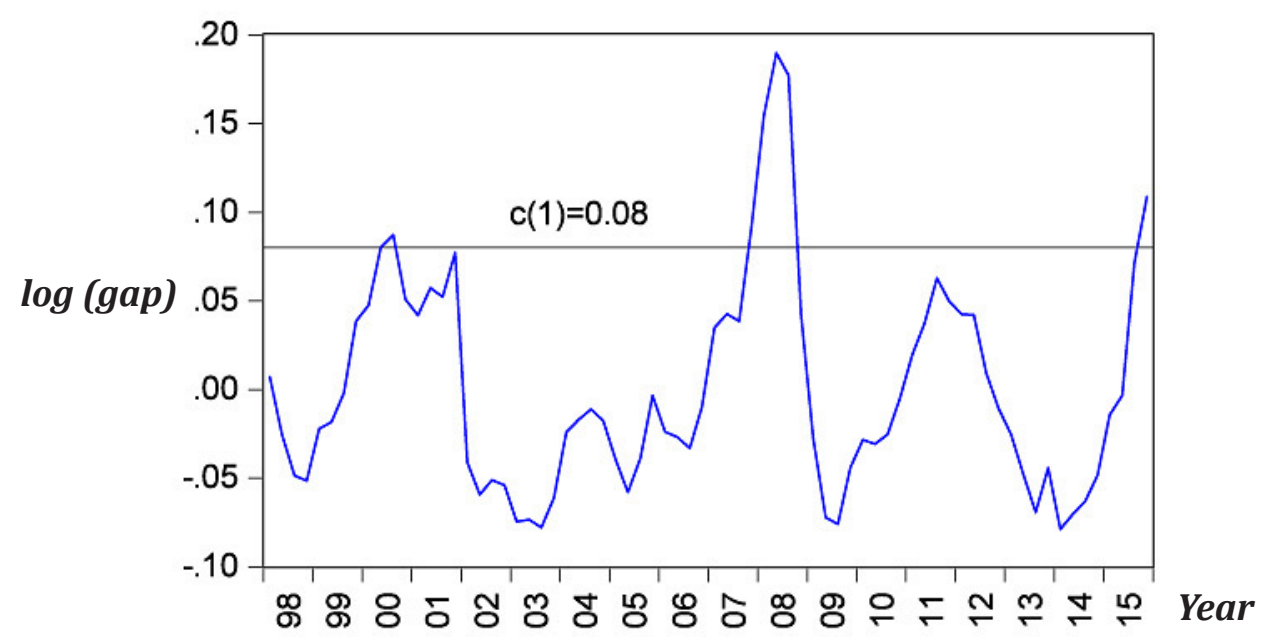




\section{References}

- Abiad A., Ostry J. (2005). Primary Surpluses and Sustainable Debt Levels in Emerging Market Countries. Working Paper, No. PDP / 05-6, IMF, Washington D.C.

- Bohn H. (1998). The Behavior of U.S. Public Debt and Deficits. Quarterly Journal of Economics, Vol. 113, No. 3, pp. $949-963$. https://doi.org/10.1162/003355398555793

- Bohn H. (2005). The Sustainability of Fiscal Policy in the United States. CESifo Working Paper Series, No. 1446.

- Bohn H. (2007). Are stationary and cointegration restrictions really necessary for the intertemporal budget constraint? Journal of Monetary Economics, Vol. 54, No. 7, pp. 1837-1847.

- Budina N., Wijnbergen, S. (2008). Quantitative approaches to fiscal sustainability analysis: a case study of Turkey since the crisis of 2001. World Bank Economic Review Vol. 23, No.1, pp. 119-140. https://doi.org/10.1093/wber/lhn011

- Burger P., Marinkov M. (2012). Fiscal rules and regime-dependent fiscal reaction functions: the South African case. OECD Journal on Budgeting, Vol. 12, No. 1, pp. 1-29. https://doi.org/10.1787/budget-12-5k9czxjth7tg

- Burger P., Stuart I., Jooste C.,Cuevas A. (2011). Fiscal sustainability and the fiscal reaction function for South Africa. Working Paper, No. 11-69, IMF, Washington D.C.

- Claeys P. (2008). Rules, and their effects on fiscal policy in Sweden. Swedish Economic Policy Review Vol. 15, No. 1, pp. 7-48.

- de Mello L. (2005). Estimating a fiscal reaction function: the case of debt sustainability in Brazil. Working Papers, No. 423, OECD Economics Department. https://doi.org/10.1787/556325773018

- Favero C., Marcellino M. (2005). Modelling and Forecasting Fiscal Variables for the Euro Area. Oxford Bulletin of Economics and Statistics, Vol. 67, No. 1, pp. 755-783. https://doi.org/10.1111/j.1468-0084.2005.00140.x

- Favero C., Monacelli T. (2005). Fiscal policy rules and regime (in) stability: evidence from the U.S. Working Paper, No. 282, IGIER.

- Gali J., Perotti R. (2003). Fiscal policy and monetary integration in Europe. Discussion Paper No. 3933, CEPR.

- Ghosh A., Kim J., Mendoza E., Ostry J., Qureshiet M. (2013). Fiscal Fatigue, Fiscal Space and Debt Sustainability in Advanced Economies. Economic Journal, Royal Economic Society 02, F4-F30, 02. https://doi.org/10.1111/ecoj.12010

- IMF (2015). Fiscal Monitor - Now Is the Time: Fiscal Policies for Sustainable Growth IMF, Washington D.C.

- Leeper E. (1991). Equilibria under active and passive monetary and fiscal policies. Journal of Monetary Economics, Vol. 27, No. 1, pp. 129-147. https://doi.org/10.1016/0304-3932(91)90007-B

- Legrenzi G., Milas C. (2013). Modelling the fiscal reaction functions of the GIPS based on state-varying thresholds. Economics Letters, Vol. 121, No. 3, pp. 384-389. https://doi.org/10.1016/j.econlet.2013.09.011

- Mendoza E., Ostry J. (2007). International evidence on fiscal solvency: Is fiscal policy responsible? Working Paper, No. 0756, IMF, Washington D.C.

- Penalver A., Thwaites G. (2006). Fiscal Rules for Debt Sustainability in Emerging Markets: The Impact of Volatility and Default Risk. Working Paper, No. 307, Bank of England. https://doi.org/10.2139/ssrn.933299

- Teräsvirta T. (1994). Specification, estimation, and evaluation of smooth transition autoregressive models, Journal of the American Statistical Association, Vol. 89, No. 425, pp. 208-218.

- Teräsvirta T. (1998). Modeling economic relationships with smooth transition regressions, in: A. Ullah and D. E. Giles, eds., Handbook of Applied Economic Statistics, New York: Dekker.

- Teräsvirta T. (2004). Smooth transition regression modeling, in: H. Lütkepohl, and M. Krätzig, eds., Applied Time Series Econometrics, Cambridge University Press. https://doi.org/10.1017/СB09780511606885.007 